\title{
Reduction in picking times orders for delivery in a national distribution center: A case study
}

\author{
Jenny Gutiérrez López, MSc. ${ }^{1}$, Álvaro Freile, MSc. ${ }^{1}$, and Sofía López Iglesias, MSc. ${ }^{1}$ \\ ${ }^{1}$ ESPOL Polytechnic University. Escuela Superior Politécnica del Litoral, ESPOL. Facultad de Ingeniería Mecánica y Ciencias de \\ Producción. Campus Gustavo Galindo km. 30.5 Vía Perimetral, P.O. Box 09-01-5863, Guayaquil, Ecuador. \\ jepiguti@espol.edu.ec, afreile@espol.edu.ec,slopez@espol.edu.ec.
}

\begin{abstract}
This case study evaluated the storage management of a consumer goods warehouse. There the cycle time to prepare an order was high (from 2 to 8 hours depending on the order type). The warehouse presented some inconveniences such as: long time to perform operations and great mobilization of people and products. Consequently, this study aims to: reduce order picking times and therefore reduce picking costs. The methodology used divided the study in two phases: current situation analysis, and improvement proposal which includes the results. During the first phase, problem solving tools were used to identify the main causes. Then, to develop the improvement proposal, a binary integer programing model was designed to present a new-more appropriate-configuration of the existing SKUs allocation within the warehouse considering type of products constraints (e.g. products belong to different families and products within a family have similar characteristics) and $A B C$ classification. The results showed that an adequate configuration of the picking area resulted in decrease of personnel mobilization, reduction of picking times and reduction of operative cost associated with picking including cost of reverse logistics.
\end{abstract} reduction.

Keywords-binary integer programming model, picking, cost

\section{INTRODUCTION}

\section{A. Motivation}

The storage stage is considered a non-value added activity in the supply chain. However, it comprises the order preparation for dispatch of finished goods. The latter activity requires a large amount of human resources and it is considered one of the most critical [1].

Distribution centers or warehouses aim to leverage supply and demand within a physical space keeping logistics costs as low as possible and pursuing a high service level [1-2].

Mainly, two aspects are considered to achieve an effective management of warehouses: an adequate management of the inventory and an adequate location of the products in the warehouse, in this way the operation and storage costs are reduced and at the same time it guarantees the satisfaction of the service provided to the client [2].

\section{B. Objective}

Decrease order preparation times, also known as picking times, in a national distribution center for mass consumption products (consumer goods) by detecting the main problems of allocation within the warehouse.

\section{Overview}

Digital Object Identifier (DOI): http://dx.doi.org/10.18687/LACCEI2019.1.1.366

ISBN: 978-0-9993443-6-1 ISSN: 2414-6390

The present work evaluates the storage management of a national distribution center of consumer goods by means of studying the cycle times of the orders. The case study is developed in a company which has high times in the preparation of dispatch orders. The development of this work includes an analysis of the current allocation of the products as well as the $\mathrm{ABC}$ classification and the picking activities of the dispatch orders. Then, causes were analyzed. Finally, the proposal involves the relocation of SKUs in the warehouse through the development of a binary integer programing model. The improvement is evaluated through different scenarios to verify the flexibility of the proposed model; as well as the impact that this improvement would have on the orders picking time.

\section{METHODOLOGY}

This work was developed in two phases. The first phase is the current situation analysis which includes; problem definition, analysis of SKUs and layout analysis. The second phase is the development of improvement proposal. The later elaborates on the binary integer programming model and its evaluation. Fig 1 shows the steps followed in this case study.
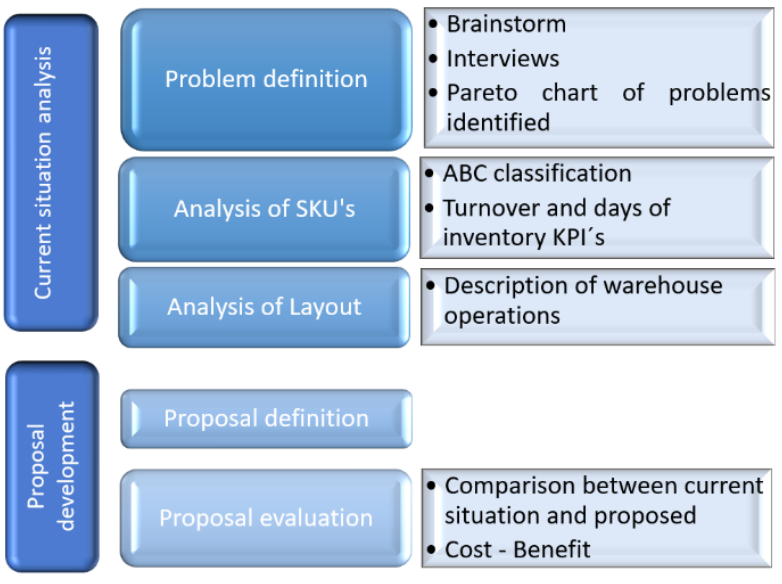

Fig. 1 Methodology for this work.

\section{CURRENT SITUATION ANALYSIS}

\section{A. Problem definition}

To define the main problem of the warehouse, we conducted three brainstorming sessions with the personnel. After these sessions, six problems were selected, and later we ranked these problems through 41 interviews. Results showed $44 \%$ of the interviewed personnel agreed that the main problem

$17^{\text {th }}$ LACCEI International Multi-Conference for Engineering, Education, and Technology: "Industry, Innovation, And Infrastructure for Sustainable Cities and Communities", 24-26 July 2019, Jamaica. 
of the warehouse was high picking times. A man-hours Pareto chart validated the issue.

The Pareto chart exhibited that $70 \%$ of the time is used in picking activities and loading orders on trucks. Moreover, it was also demonstrated that the picking is the second most expensive activity in the warehouse under study. Consequently, the problem we will analyze is high picking times on orders to dispatch.

\section{B. The Company: Case Study}

The company has a long history in the production and distribution of consumer goods in Ecuador. The national distribution center under study has a total of 74 SKUs, which are distributed as follows: 27 in the presentation of boxes, 17 in liters, 17 trays, and 13 buckets.

There are four different types of orders, the order size determine the capacity of the truck and it is related to the storage capacity of the customers. There are certain orders that require the whole pallet, in that cases preparation is not necessary. When it is required, the order preparation includes picking products in the warehouse and arranging new pallets with the necessary products in the order.

To further confirm that preparation of an order is an issue due to the high times needed, we analyzed the order cycle splitting it in three parts: administrative processing of the order, preparation of the order and load of the order on trucks. Fig 2 shows the order cycle times per order type indicating that in the four order types the preparation of the order is the activity that requires most of the time.

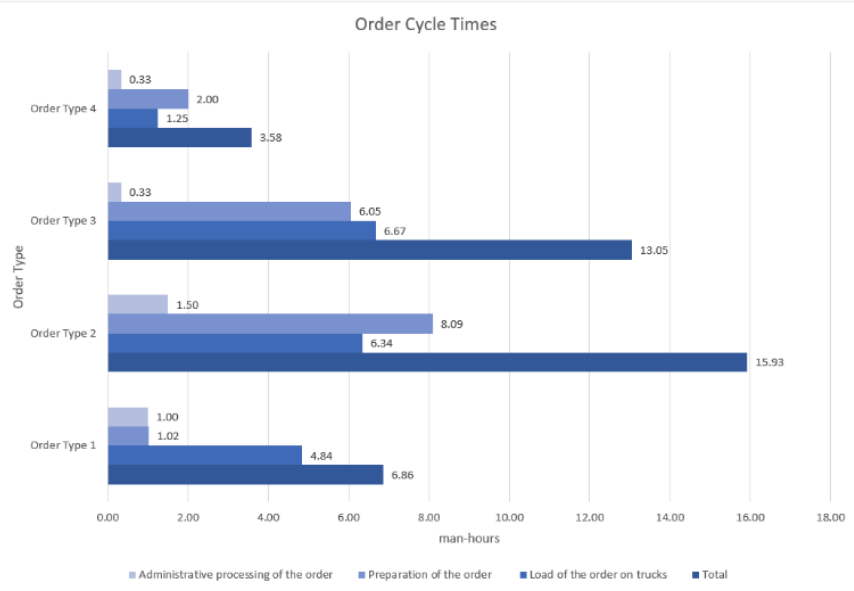

Fig. 2 Order cycle times in man hours

\section{Layout Analysis}

In Fig. 3, the layout of the warehouse is shown. The diagram also shows entry and exit doors; as well as the halls or corridors available for movement of people and products. The warehouse under study has a capacity to storage 2,308 pallets, Fig. 3 shows that there is one entry door and two exit doors towards the pre-chamber. The lift truck transits along these doors. The warehouse has six halls or corridors. Hall 1 uses simple racks, while the rest of the areas uses double-depth racks. Storage racks have 5 levels (height). Halls from 1 to 4 storage reserve products.

In hall 3 there are trays in the first level, in hall 4 the buckets are stored in the first level, in hall 5 and 6 the first level is exclusively used for picking products and in the rest of the positions any type of SKU is placed. Since trays are mostly storage in pallets, they do not require significant preparation times and are not considering in this work.

Fig. 3 shows in dotted lines the routes that operators follow while preparing the order. The route begins in the pre-chamber, and depending on what is in the order, the operator goes to hall 6 or hall 5 . Once inside the warehouse, the operator places the empty pallet in one of the positions marked with a circle in Fig. 3 , in such a way that the SKUs to be placed on the pallet are closest to the chosen preparation point.

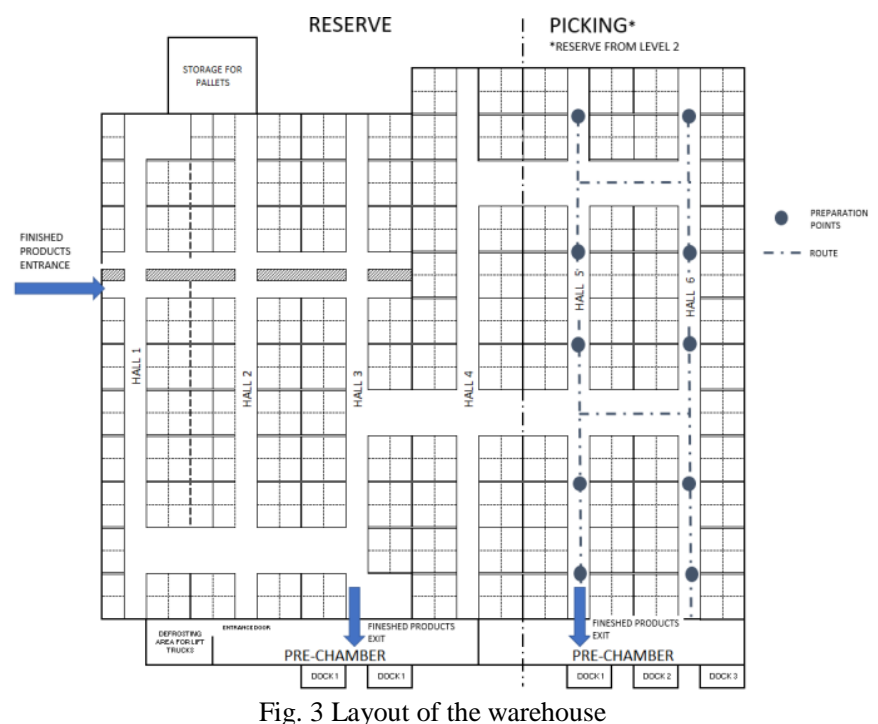

D. SKUs Analysis

The warehouse is divided in two sections: reserve and picking. We performed similar analysis for both, however, in this article we are only presenting the analysis that refers to picking area. For any details regarding the reserve area analysis, refer to [3].

The ABC analysis is performed according to the average demand per pallet per month based on historical data of one year. For the picking area there are 82 positions divided into 3 families: 32 positions for boxes, 36 positions for liters and, 14 positions for buckets. The picking area handles 57 SKUs of which:

- 27 items belong to classification A, high demand.

- 14 items belong to classification B, medium demand.

- 16 items belong to classification $\mathrm{C}$, low demand.

Fig. 4 shows the picking layout after performing the ABC analysis. The highest proportion of products belong to the category A. For this area, it is known that all SKUs will be 
stored in level 1, which is the level exclusively destined for picking, and the products are in halls 5 and 6 .

The turnover rate was determined based on the average demand and the average monthly stock, calculated according to historical data. For the picking area the turnover rates are high (higher than 10 for class A). This is due to the limited positions in this piking area. This sector is intended to only two halls. Therefore, the average stock that is maintained for these SKUs moves more frequently.

The days of inventory measures has an inverse function to the turnover rate, meaning that the lower the degree of turnover, the greater the days of inventory. Then, the analysis showed that the items with the greatest days of inventory are mostly in the classification $\mathrm{C}$.

All items with days of inventory greater that 7 are in category C. In this category, the largest measure is 20 days. In addition, results demonstrated that days of inventory are small in the picking area which was expected since this area has limited positions. Consequently, it is necessary to make frequent replenishment in this area

SKUs analysis showed that in the picking area turnover rates are high while days of inventory are small. Both characteristics suggest a rapid operation in the warehouse for this area. On the other hand, although the warehouse is sectioned according to the families (boxes, liters and buckets), the location of the SKUs within each section does not follow an order. Within the family of boxes there are products that are similar to each other, either by name, presentation or weight; these products cannot be stored adjacently as this generates errors at the time of order preparation. This highlights the importance of an efficient operation for preparation of orders.

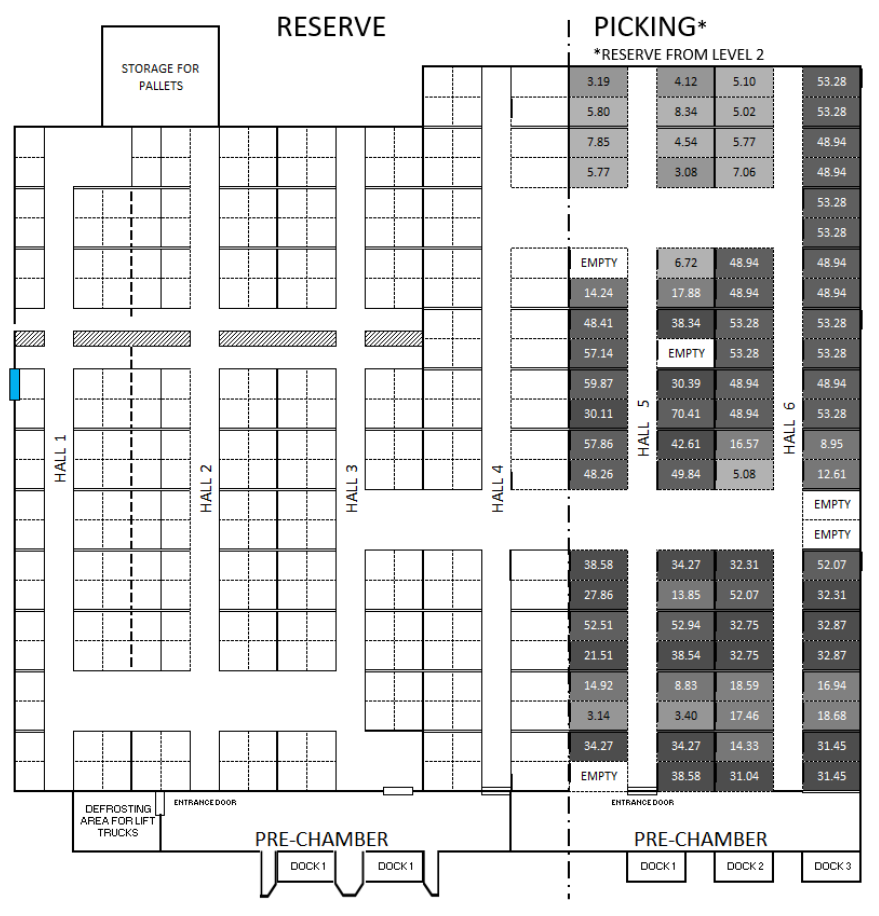

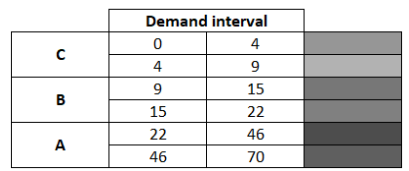

Fig. 3 Location of the products according to the $\mathrm{ABC}$ classification represented by grayscale; the darker gray tone represents those products with

the highest demand (A), the intermediate gray ones are the SKUs with demand $\mathrm{B}$ and the light gray ones correspond to the products of demand $\mathrm{C}$.

\section{E. Causes identification}

Table I shows the main causes found after using techniques such as: brainstorming, Ishikawa and the prioritization matrix. These causes were obtained together with the operators and administrative staff of the warehouse. The possible solutions to correct each of them are indicated [3].

TABLE I

\begin{tabular}{|c|c|}
\hline \multicolumn{2}{|c|}{ SOLUTIONS PER CAUSE } \\
\hline Root Causes & Solution \\
\hline $\begin{array}{l}\text { There is no proper designation } \\
\text { of picking capacity for SKUs. }\end{array}$ & $\begin{array}{l}\text { Capacity allocation according } \\
\text { to turnover rate and days of } \\
\text { inventory. }\end{array}$ \\
\hline $\begin{array}{l}\text { The assignment of SKUs does } \\
\text { not follow an order. Random } \\
\text { assignment of SKUs in the } \\
\text { warehouse }\end{array}$ & $\begin{array}{l}\text { Perform and } \mathrm{ABC} \text { analysis in } \\
\text { terms of demand and relocate } \\
\text { the SKUs. }\end{array}$ \\
\hline $\begin{array}{l}\text { There are no criteria for the } \\
\text { location of similar products. }\end{array}$ & $\begin{array}{l}\text { Perform a compatibility } \\
\text { analysis and train staff. }\end{array}$ \\
\hline $\begin{array}{l}\text { Picking location has not been } \\
\text { determined. }\end{array}$ & $\begin{array}{l}\text { Relocation of SKUs in the } \\
\text { warehouse and staff training. }\end{array}$ \\
\hline $\begin{array}{l}\text { There is no location order of } \\
\text { the products. }\end{array}$ & $\begin{array}{l}\text { Perform an } \mathrm{ABC} \text { analysis and } \\
\text { relocate the products. }\end{array}$ \\
\hline
\end{tabular}

In this work we developed the solutions that satisfied most of the causes. These solutions were to perform an $\mathrm{ABC}$ analysis and relocate the SKUs in the warehouse. In addition, it was necessary to work on the training of the administrative and operational staff of the warehouse regarding the changes in the locations of the products.

An integer programming model will be used as a solution strategy for the relocation of the SKUs within the warehouse.

\section{PROPOSAL DEFINITION}

\section{A. Model Formulation}

In this case products are divided in classes which are called families, and these are: liters, boxes, and buckets. The warehouse storages products based on the class, with random storage within each class.

The picking area has its own positions for these three groups. There are 82 double depth positions and it is proposed to distribute them as follows: 44 for boxes, 25 for liters, and 13 for buckets.

We work with a global programming model, based on the model in [4], [5], [6]. 
Assumptions:

- The warehouse handle 74 SKUs, but only 57 of them require storage in the picking area.

- The number of pallets required by SKU is known.

- The warehouse is divided into three parts; therefore, groups are formed with the positions and the SKUs corresponding to each family. These are considered as input parameters.

- The positions are pre-established, that is, the number of columns and the storage levels do not vary.

- The first level for hall 5 and 6 is used only for picking activity.

- There are 10 preparation points and the distances form each position to the different preparation points is known and rectilinear.

\section{Parameters:}

$S_{j}:$ Number of positions required for product $j$.

$T_{j}$ : Number of trips per product $j$.

$d_{k i}$ : Distance required to go from position $k$ to preparation point $i$.

$P_{1}$ : Set of positions corresponding to family 1 .

$P_{2}$ : Set of positions corresponding to family 2 .

$P_{3}$ : Set of positions corresponding to family 3 .

$F_{1}$ : Set of products corresponding to family 1 .

$F_{2}$ : Set of products corresponding to family 2 .

$F_{3}$ : Set of products corresponding to family 3 .

$C$ : $N x N$ binary matrix with component $c_{j j}$, equal to 1 when the product $j$ is similar to the product $j$ ' otherwise, 0 .

\section{Indexes:}

$k$ : position index $k=1,2, \ldots p$

$j$ : product or SKUs index $j=1,2, \ldots n$

$i$ : preparation point index $i=1,2, \ldots m$

\section{Variables:}

$x_{j k i}$ : binary variable that is 1 if product $j$ is in position $k$ and is prepared in point $i$, otherwise it is 0 .

\section{Objective function}

$$
\text { Minimize } Z: \sum_{j=1}^{n} \sum_{k=1}^{p} \frac{T_{j}}{S_{j}}\left(\sum_{i=1}^{m} d_{k i} x_{j k i}\right)
$$

s.t.

$$
\begin{aligned}
& \sum_{j \in F_{1}} \sum_{i=1}^{m} x_{j k i} \leq 1 ; \quad k \in P_{1} \\
& \sum_{j \in F_{2}} \sum_{i=1}^{m} x_{j k i} \leq 1 ; \quad k \in P_{2} \\
& \sum_{j \in F_{3}} \sum_{i=1}^{m} x_{j k i} \leq 1 ; \quad k \in P_{3}
\end{aligned}
$$

$$
\begin{aligned}
& \sum_{k=1}^{p} \sum_{i=1}^{m} x_{j k i}=S_{j} ; j=1,2, . . n \\
& \sum^{m} \\
& \sum_{i=1} x_{j k i}=0 ; \quad k \in P_{2} \quad j \in F_{1} \\
& \sum_{\substack{i=1 \\
m}}^{m} x_{j k i}=0 ; \quad k \in P_{3} \quad j \in F_{1} \\
& \sum_{i=1}^{m} x_{j k i}=0 ; k \in P_{1} \quad j \in F_{2} \\
& \sum_{\substack{i=1 \\
m}}^{m} x_{j k i}=0 ; k \in P_{3} \quad j \in F_{2} \\
& \sum_{i=1}^{m} x_{j k i}=0 ; \quad k \in P_{1} \quad j \in F_{3} \\
& \sum_{i=1}^{m} x_{j k i}=0 ; k \in P_{2} \quad j \in F_{3} \\
& \sum_{i=1}^{m}\left(c_{j j \prime} x_{j k i}+c_{j j \prime} x_{j \prime(k+1) i}\right) \leq 1 ; k \in P_{1} \text {, } \\
& j \in F_{1}, j^{\prime} \in F_{1} \\
& x_{j k i} \in(0,1) \quad \nabla \mathrm{j}, \mathrm{k}, \mathrm{i}
\end{aligned}
$$

The objective function (1) minimizes the distances traveled to the preparation points according to the frequency of visits to each position.

The constraints (2), (3), (4), ensure the allocation of only one product or SKU for each position in the sections designated by family, in this way in both depths of each position will be a single product. Constraint (5) implies the assignment of the positions required by each SKU, ensuring that they are not allocated more than necessary. Constraint (6) assigns the value of zero for the locations of the products of family 1 in the positions corresponding to family 2 , in this way it ensures that the SKUs are located exclusively in the positions designated for each family. The same function has the constraints (7), (8), (9), (10), and (11).

Constraint (12) ensures that within family 1, similar products are not placed adjacently, thus avoiding confusion when preparing orders; this constraint only applies to family 1 since it is only in that family that there are products with similar characteristics.

Finally, constraint (13) indicates that the variable that is handle is binary.

\section{B. Model Solution}

The model described in the previous section was solved in the GAMS software (General Algebraic Modeling System), which is a program that allows the resolution of complex mathematical models. Due to the size of the proposed model, the student version of the software could not find a solution. Therefore, an online solver was used, using a tool provided by the University of Wisconsin-Madison, Neos Solver, which is a 
portal that presents a list of solvers for mathematical problems depending on their type and supports different languages. In this case, the problem proposed is an integer programming problem; and the Gurobi solver was used for the resolution [7].

\section{Picking Proposal}

The results obtained from the mathematical model, showed the location of each of the 57 SKUs in the different positions at the warehouse.

It should be noted that the SKUs were assigned by family according to the sections in which the warehouse is divided. In addition, we proceeded to verify that the constraints described in the model were met; regarding similarities between products and assignment of only one SKU per position. The layout proposed for picking is presented in Fig. 4, where brown color represents boxes, blue color is liters and white is buckets. Products or SKUs are presented in the figure indicating their demand. The demand is considered per pallet per month based on historical data of one year.

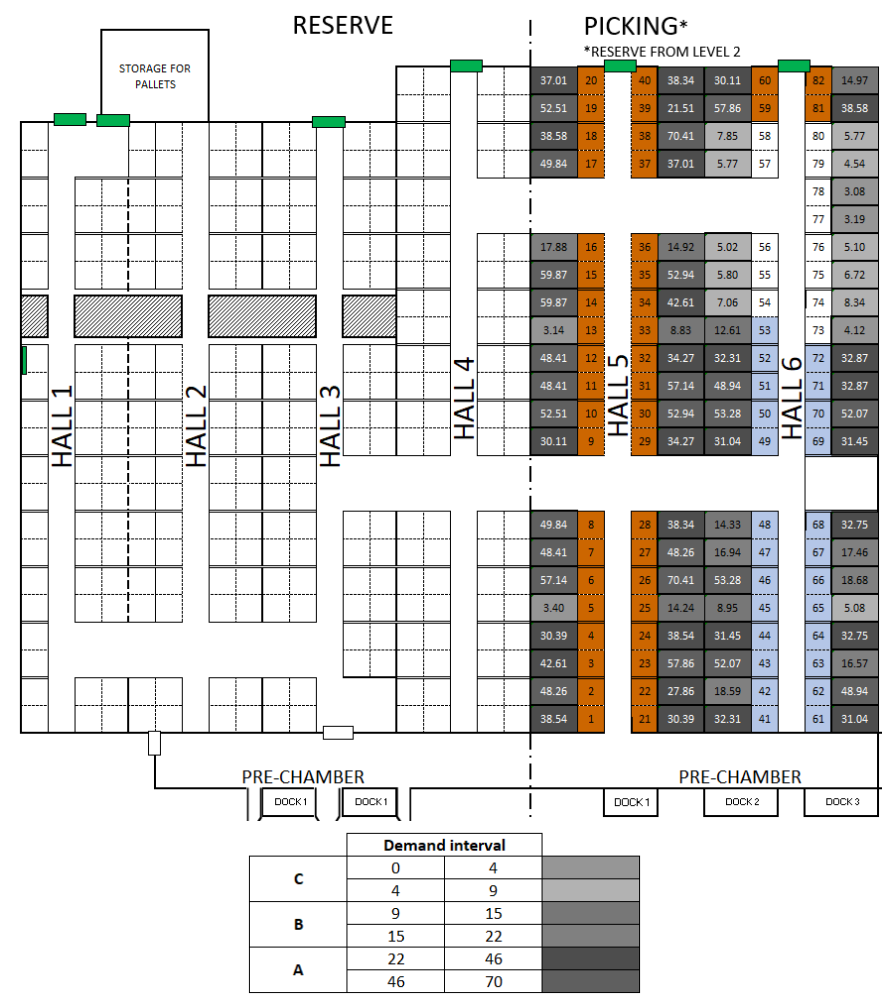

Fig. 4 Results of the proposed distribution in picking according to the mathematical model and location of the products according to the $\mathrm{ABC}$ classification represented by grayscale.

\section{Proposal EVALUATION}

Due to time constraints it was not possible to implement the changes in the warehouse. For that reason, we simulate the results to conduct proper comparisons. However, in this section we provide some ideas to consider when conducting the implementation.

\section{A. Comparison current situation vs proposed}

Once the proposal of relocation of SKUs for the picking area is obtained, the expected impact of the improvements is measured. A comparison is performed analysing the order types. Recall that for the picking area there are 3 types of orders. A sample of each order is taken and the preparation time for each order is estimated in the current situation and in the proposal.

It should be mentioned that the orders selected for the comparisons are typical orders that are presented in each case. Regarding the size of the order, the chosen ones are not the biggest or the smallest, they are normal orders. For order type 2, the order selected has 4,500 units of 48 different SKUs; order type 3 has 1,212 units of 49 different SKUs; and finally order type 4 has 681 units of 37 different SKUs.

The relocation of the SKUs proposed in this work, has an impact on the distances travelled during the preparation of orders, which is reflected in the times of transfers, both loaded and unloaded as is presented in Table II.

\section{B. Costs and operational implications}

It is necessary to coordinate with the finance department to carry out an inventory of the warehouse before initiating the relocation of the SKUs for a better control of the stocks. In addition, the warehouse personnel should review the system to match the quantities and locations between the situation before and after the relocation.

The reallocation of products was performed during the first week of the month; when the warehouse is used at its lower capacity -due to the nature of the business-. Warehouse operators can perform the movements during regular working days.

TABLE II

CURRENT TIME ORDER PREPARATION AND PROPOSED

\begin{tabular}{|c|c|c|}
\hline \multicolumn{3}{|c|}{ Order Type 3 } \\
\hline & Current & Proposal \\
\hline Total Preparation Time & $5.86 \mathrm{~h}$ & $5.26 \mathrm{~h}$ \\
\hline Percentage of variation & \multicolumn{2}{|c|}{$-10.33 \%$} \\
\hline \multicolumn{3}{|c|}{ Order Type 4} \\
\hline & Current & Proposal \\
\hline Total Preparation Time & $2.63 \mathrm{~h}$ & $2.40 \mathrm{~h}$ \\
\hline Percentage of variation & $-8.81 \%$ \\
\hline \multicolumn{3}{|c|}{ Order Type 2 } \\
\hline \multicolumn{2}{|c|}{ Current } & Proposal \\
\hline Total Preparation Time & $7.30 \mathrm{~h}$ & $6.82 \mathrm{~h}$ \\
\hline Percentage of variation & $-6.49 \%$ \\
\hline
\end{tabular}

\section{Benefits}

The implementation of the proposal would lead to other benefits besides the reduction of the preparation times of orders; for example: organization in the warehouse, less errors when preparing an order (e.g. dispatching incorrect products), and less movements of personnel in the warehouse.

Moreover, the proposal has a positive impact on the health of the personnel that works in the warehouse, since by

$17^{\text {th }}$ LACCEI International Multi-Conference for Engineering, Education, and Technology: "Industry, Innovation, And Infrastructure for Sustainable Cities and Communities", 24-26 July 2019, Jamaica. 
improving the preparation activity, people need less time to be exposed to the cold of the warehouse (in this case the products are required to be on low temperatures). On the other hand, the personnel can use the time to perform other activities such as: maintenance, cleaning, inventory, among others. The implementation would present savings of 3.64 man-hours per day as shown in Table III.

To translate the savings in Table III to dollars on a monthly basis, we use the percentage decreased to calculate the current and proposed times. Table IV shows that the monthly operating costs would be reduced by approximately $10 \%$.

Another important benefit is presented at the end of the month when the number of daily prepared orders increases approximately twice, since the demand for those days is greater. Results showed that same workers can manage pick demands and less workers need overtime. The times for these three days at the end of the month are presented in Table V.

TABLE III

EXPECTED IMPROVEMENTS FROM THE IMPLEMENTATION OF THE MODEL

\begin{tabular}{|c|c|c|c|}
\hline \multicolumn{4}{|c|}{ Times per daily order (man-hours) } \\
\hline & Current & Proposal & Savings \\
\hline Order Type 3 & 12.84 & 11.51 & 1.33 \\
\hline Order Type 4 & 15.84 & 14.44 & 1.40 \\
\hline Order Type 2 & 13.76 & 12.84 & 0.92 \\
\hline
\end{tabular}

TABLE IV

EXPECTED MONETARY BENEFITS

\begin{tabular}{|c|c|cc|ccc|}
\hline \multicolumn{8}{|c|}{ Monthly operating times } \\
\hline & $\begin{array}{c}\text { Costs } \\
\text { man }- \\
\text { hours } \\
(\$)\end{array}$ & $\begin{array}{c}\text { Required } \\
\text { time } \\
\text { (man }- \\
\text { hours })\end{array}$ & $\begin{array}{c}\text { Total } \\
\text { Cost } \\
(\$)\end{array}$ & $\begin{array}{c}\text { Time } \\
\text { reduced }\end{array}$ & $\begin{array}{c}\text { Required } \\
\text { time } \\
\text { (man }- \\
\text { hours })\end{array}$ & $\begin{array}{c}\text { Total } \\
\text { Cost } \\
(\$)\end{array}$ \\
\hline $\begin{array}{c}\text { Order } \\
\text { Type 3 }\end{array}$ & 1.88 & 321 & 603.48 & $10.33 \%$ & 282 & 531.03 \\
\hline $\begin{array}{c}\text { Order } \\
\text { Type 4 }\end{array}$ & 1.88 & 396 & 744.48 & $8.81 \%$ & 360 & 677.18 \\
\hline $\begin{array}{c}\text { Order } \\
\text { Type 2 }\end{array}$ & 1.88 & 344 & 646.72 & $6.69 \%$ & 317 & 596.44 \\
\hline
\end{tabular}

TABLE V

TIMES PER DAILY ORDER AT THE END OF THE MONTH

\begin{tabular}{|c|c|c|c|}
\hline \multicolumn{4}{|c|}{ Times per daily order (man-hours) } \\
\hline & Current & Proposal & Savings \\
\hline Order Type 3 & 25.68 & 23.03 & 2.65 \\
\hline Order Type 4 & 31.68 & 28.89 & 2.79 \\
\hline Order Type 2 & 27.52 & 25.68 & 1.84 \\
\hline
\end{tabular}

Thus, in these last days of the month there would be savings of 7.28 man-hours per day, which implies that in three days there would be a saving of 22 man-hours. Therefore, the implementation of the proposal would reflect an $8 \%$ reduction in overtime at the end of the month equivalent to 2 people.

On the other hand, it is known that currently employing 22 people in shifts of 12 hours, there is a cost of overtime annually of $\$ 10,050.48$ and with the proposal it is suggested to work with 20 people in 12-hour shifts with an annually overtime cost of $\$ 9,136.8$. Then, it is expected to save $\$ 913.68$ per year in overtime, or $9 \%$ of the costs for overtime.
Moreover, we estimate that the model will reduce $75 \%$ of returns due to bad orders. The latter results in approximately $\$ 11$ thousand/year savings in reverse logistics, after placing SKUs with similar appearance far form each other.

\section{CONCLUSIONS}

This work proposes an improvement alternative to reduce preparation times in picking activities in a warehouse. The warehouse under study presented high preparations times and was catalogued as the main problem according to the personnel. This problem was confirmed with data as we elaborated Pareto Charts.

As a solution, we proposed to conduct an $\mathrm{ABC}$ analysis and to relocate the SKUs in the warehouse. Moreover, it was suggested to train the personnel regarding the location's changes of products in the warehouse.

The relocation of the SKUs in the warehouse was performed through the formulation of a mathematical model. The model used is an integer linear programming problem which was coded in GAMS and solved in an online platform called Neos Solver.

For the picking area there are savings of 3.64 man-hours per day. For the order type 3, a reduction in preparation times of $10.33 \%$ is obtained, order type $48.81 \%$ and order type 2 reductions of $6.69 \%$ in times.

The implementation of the new locations assigned by the model represent reductions in costs of approximately $10 \%$ (\$ 190) per month. In addition, savings in overtime at the end of the month of 7.28 man-daily hours ( 2 people); that is, a $9 \%$ decrease in the costs of overtime paid at the end of the month. Another quantifiable savings refers to less errors when preparing an order, these errors can be reduced by $75 \%$ with potential savings of $\$ 11$ thousand/year.

Other benefits, in addition to the reduction of time and operating costs are organization in the warehouse, reduction of staff movements and impact on the health of workers.

\section{RECOMMENDATIONS}

It is recommended to establish strategies to reduce the days of inventory of low demand products to better use the space in the warehouse. This will provide the opportunity to storage other items that are most requested. Other strategies can also be developed on the standardization of processes related to order preparation activities, avoiding the complexities that hinder the dispatch of orders.

Also, it is suggested to adapt the binary integer programming model so that besides determining the location of SKU, it defines the optimum quantities of product in the picking area and the ideal number of people to fulfil the activity in the desired time.

Finally, to further improve the warehouse it is advised to perform an inventory management analysis through a push system to determine the appropriate quantities to store in the warehouse. 


\section{REFERENCES}

[1] Carreño Solís, Adolfo. "Logística de la A a la Z", Fondo Editorial de la Pontificia Universidad Católica del Perú, 2011, Lima, Perú.

[2] F. Guerriero, R. Musmanno, O. Pisacane, and F. Rende. 2012. A Mathematical model for the Multi-level's product allocation problem in a warehouse with compatibility constraints.

[3] Freile Pazmiño, Álvaro José; Gutiérrez López, Jenny Pilar (2015). Reduction in picking times orders for delivery in a national distribution center. Undergraduate Thesis (in Spanish). Industrial Engineering. Espol Fimcp, Guayaquil. 142.

[4] Frederick S. Hillier y Gerald J. Lieberman. Introducción a la Investigación de Operaciones. Novena Edición. 2010. McGraw-Hill Companies, Inc.

[5] Sanei, O., Nasiri,V., Marjani, M.R., Moaltar Husseini, S.M. A heuristic algorithm for the warehouse space assignment problem considering operational constrains with application in a case study. Proceedings of the 2011 International Conference on Industrial Engineering and Operations Management. Kuala Lumpur, Malaysia, January 22 - 24, 2011. Pág. 258 264.

[6] Tompkins, White, Bozer, Tanchoco. Facilities Planning, 2010. Cuarta Edición. John Wiley \& Sons, Inc.

[7] University of Wisconsin in Madison. Wisconsin Institutes for Discovery. NEOS Server. 2014, http://www.neos-server.org/neos/

$17^{\text {th }}$ LACCEI International Multi-Conference for Engineering, Education, and Technology: "Industry, Innovation, And Infrastructure for Sustainable Cities and Communities”, 24-26 July 2019, Jamaica. 